\title{
Tulane
}

\author{
Tulane Economics Working Paper Series
}

\section{Do Ethics Matter? Tax Compliance and Morality}

\author{
James Alm \\ Department of Economics \\ Tulane University \\ New Orleans, LA \\ jalm@tulane.edu
}

\author{
Benno Torgler \\ School of Economics and Finance \\ Queensland University of \\ Technology \\ Brisbane, Australia \\ benno.torgler@qut.edu.au
}

Working Paper 1207

July 2012

\begin{abstract}
In this paper we argue that puzzle of tax compliance can be explained, at least in part, by recognizing the typically neglected role of ethics in individual behavior; that is, individuals do not always behave as the selfish, rational, self-interested individuals portrayed in the standard neoclassical paradigm, but rather are often motivated by many other factors that have as their main foundation some aspects of "ethics". We argue that it is not possible to understand fully an individual's compliance decisions without considering in some form these ethical dimensions. Specifically, we argue here that there is much direct and indirect evidence that ethics differ across individuals and that these differences matter in significant ways for their compliance decisions. We then put this in the larger context of the inability of the standard neoclassical paradigm to explain compliance of at least some individuals, and we suggest several possible avenues by which theory can be expanded to incorporate ethics. We conclude by arguing that a full house of compliance strategies is also needed to combat tax evasion, strategies that include the traditional "enforcement" paradigm suggested by and consistent with neoclassical theory, a less traditional "service" paradigm that recognizes the important role of a "kinder and friendlier" tax administration in encouraging compliance, and, importantly, a new "trust" paradigm that is built on the foundation of ethics, in which the tax administration must recognize that it can erode the ethics of taxpayers by its own decisions.
\end{abstract}

Keywords: economics of crime, ethics, expected utility theory, tax evasion, behavioral economics, social norms, tax morale

JEL: H26, H31 


\title{
DO ETHICS MATTER?
}

\section{Tax Compliance and Morality}

\author{
James Alm and Benno Torgler*
}

\begin{abstract}
In this paper we argue that puzzle of tax compliance can be explained, at least in part, by recognizing the typically neglected role of ethics in individual behavior; that is, individuals do not always behave as the selfish, rational, self-interested individuals portrayed in the standard neoclassical paradigm, but rather are often motivated by many other factors that have as their main foundation some aspects of "ethics". We argue that it is not possible to understand fully an individual's compliance decisions without considering in some form these ethical dimensions. Specifically, we argue here that there is much direct and indirect evidence that ethics differ across individuals and that these differences matter in significant ways for their compliance decisions. We then put this in the larger context of the inability of the standard neoclassical paradigm to explain compliance of at least some individuals, and we suggest several possible avenues by which theory can be expanded to incorporate ethics. We conclude by arguing that a full house of compliance strategies is also needed to combat tax evasion, strategies that include the traditional "enforcement" paradigm suggested by and consistent with neoclassical theory, a less traditional "service" paradigm that recognizes the important role of a "kinder and friendlier" tax administration in encouraging compliance, and, importantly, a new "trust" paradigm that is built on the foundation of ethics, in which the tax administration must recognize that it can erode the ethics of taxpayers by its own decisions.
\end{abstract}

KEY WORDS: economics-of-crime, ethics, expected utility theory, tax evasion.

\footnotetext{
${ }^{*}$ Andrew Young School of Policy Studies, Georgia State University, Atlanta, Georgia, USA; Queensland University of Technology, Brisbane, AUSTRALIA.
} 
We few - lagging many decades behind sociologists and social psychologists and literary folkhave finally noticed the ethical soil in which an economy grows. We came to the understanding through economic history ..., through experimental economics or economic policy, through confrontations with personal faith, political and religious. A theory of moral sentiments beyond utilitarianism requires stepping outside of economics. You can see it better there.

- McCloskey (2006)

\section{Introduction}

Although it is commonly said that the only things certain in life are death and taxes, it is nonetheless also certain that taxes are far from inevitable. Individuals do not like paying taxes, they take a variety of actions to reduce their tax liabilities, and on many occasions they succeedget away with it. Tax evasion consists of illegal and intentional actions taken by individuals and firms to reduce their legally due tax obligations, by underreporting incomes, sales, or wealth, by overstating deductions, exemptions, or credits, or by failing to file appropriate tax returns. Although measuring tax evasion is notoriously difficult, there is widespread evidence that tax evasion is extensive and commonplace in nearly all countries. ${ }^{1}$

Still, the puzzle of tax compliance is not why there is so much cheating. Instead, the real puzzle is why there is so little cheating. Typically, the percent of all individual income tax returns that are audited is often less than one percent, and the penalties on even fraudulent evasion are only a fraction of unpaid taxes. Virtually all economic models of taxpayer behavior conclude that there should be much more tax evasion than is actually observed. However, most people pay most of their taxes most of the time. The puzzle of tax compliance is to explain why people pay taxes.

In this paper we argue that this compliance puzzle can be explained, at least in part, by recognizing the typically neglected role of ethics in individual behavior; that is, individuals do

\footnotetext{
${ }^{1}$ See Schneider and Enste (2000) for discussions and applications of various approaches to measurement. All of
} 
not always behave as the selfish, rational, self-interested individuals portrayed in the standard neoclassical paradigm, but rather are often motivated by many other factors that have as their main foundation some aspects of morality, social norms, altruism, fairness, or the like, factors that we broadly - and somewhat inaccurately - classify as "ethics". We argue that it is not possible to understand fully an individual's compliance decisions - or indeed, an individual's choices more broadly - without considering in some form these ethical dimensions and their implications for behavior. As argued by Feinstein (2007), “[v]irtues are alive and well..., recognized as normative guides to conduct that are and should be important in guiding behavior in many contexts".

Specifically, we argue here that there is much direct and indirect evidence - theoretical, experimental, and empirical - that ethics differs across individuals and that these differences matter in significant ways for their compliance decisions. We then put this in the larger context of the inability of the standard neoclassical paradigm to explain compliance of at least some individuals; that is, we argue that there is a "full house" of behaviors that needs explanation,-_and that a full house of theories is needed to do this, and we suggest several possible and, we believe, promising avenues by which these new theories might proceed. We conclude by arguing that a "full house" of compliance strategies is also needed to combat tax evasion, strategies that include the traditional "enforcement" paradigm suggested by and consistent with neoclassical theory, a less traditional "service" paradigm that recognizes the important role of a "kinder and friendlier" tax administration in encouraging compliance, and, importantly, a new "trust" paradigm that is built on the foundation of ethics, in which the tax administration needs to be aware that it can erode the ethics of taxpayers by its own decisions (e.g., offering repeated tax amnesties or 
engaging in corruption). We also suggest some specific activities that the tax administration may take to increase trust.

\section{Do Ethics Matter? Some Evidence}

\section{Evidence from Theory}

The basic theoretical model used in nearly all research on tax compliance begins with the economics-of-crime model of Becker (1968), first applied to tax compliance by Allingham and Sandmo (1972). ${ }^{2}$ Here a rational individual is viewed as maximizing the expected utility of the tax evasion gamble, weighing the risky benefits of successful cheating against the also risky prospect of detection and punishment.

To illustrate this approach more precisely, consider a simple version of the standard model. An individual is assumed to receive a fixed amount of income $I$, and must choose how much of this income to declare to the tax authorities and how much to underreport. The individual pays taxes at rate $t$ on every dollar $D$ of income that is declared, while no taxes are paid on underreported income. However, the individual may be audited with a fixed probability $p$; if audited, then all underreported income is discovered, and the individual must pay a penalty at rate $f$ on each dollar that he was supposed to pay in taxes but did not pay. The individual's income $I_{C}$ if caught underreporting equals

$$
\text { (1) } \quad I_{C}=I-t D-f[t(I-D)] \text {, }
$$

or income less taxes paid on reported income less penalties on unreported taxes. If underreporting is not caught, income $I_{N}$ is

$$
\text { (2) } \quad I_{N}=I-t D
$$

\footnotetext{
${ }^{2}$ See Cowell (1990), Andreoni, Erard, and Feinstein (1998), Alm (1999), and Slemrod and Yitzhaki (2002) for
} 
or income less taxes paid on reported income. The individual is assumed to choose declared income to maximize expected utility, defined as

$$
E U(I)=p U\left(I_{C}\right)+(1-p) U\left(I_{N}\right)
$$

where $E$ is the expectation operator and utility $U(I)$ is a function only of income. This optimization generates a standard first-order condition for an interior solution; given concavity of the utility function, the second-order condition is satisfied. Comparative statics results are easily derived. For example, it is straightforward to show that an increase in the probability of detection $p$ and the penalty rate $f$ unambiguously increase declared income.

This economics-of-crime approach therefore gives the sensible result that compliance depends upon enforcement. However, it is essential to recognize that this approach also concludes that an individual pays taxes because - and only because - of the economic consequences of detection and punishment. This is a plausible insight, with the obvious implication that the government can encourage greater tax compliance by increasing the audit and the penalty rates.

However, it is clear to many observers that compliance cannot be explained entirely by such purely financial considerations, especially those generated by the level of enforcement (Graetz and Wilde, 1985; Skinner and Slemrod, 1985; Elffers, 1991). The percentage of individual income tax returns that are subject to a thorough tax audit is generally quite small in most countries, almost always well less than 1 percent of all returns. ${ }^{3}$ Similarly, the penalty on

comprehensive surveys and detailed discussions.

${ }^{3}$ For example, in the United States the percentage of individual tax returns that were audited by the Internal Revenue Service (IRS) in the 1960s was about 6 percent, and this percentage fell to 2.5 percent by the mid-1970s. Over the next decade, the audit rate fell further to roughly 1 percent and, according to the Inspector General for Tax Analysis report in 2002, taxpayer audit rates fell a further 56 percent between 1997 and 2001. Recently audit rates have increased slightly. However, while overall audit rates are quite low, among certain income and occupation classes they are more frequent, so that the often-reported IRS audit rate is somewhat of an understatement because the reported rate usually refers to full audits. In fact, the IRS conducts a wide range of audits including line matching and requests for information, and these other audits are much more frequent. In 2005 only 1.2 million individual 
even fraudulent evasion seldom exceeds more than the amount of unpaid taxes, and these penalties are infrequently imposed; civil penalties on non-fraudulent evasion are even smaller. A purely economic analysis of the evasion gamble suggests that most rational individuals should either underreport income not subject to source withholding or over claim deductions not subject to independent verification because it is unlikely that such cheating will be caught and penalized. However, even in the least compliant countries evasion seldom rises to levels predicted by a purely economic analysis, and in fact there are often substantial numbers of individuals in most countries who apparently pay all (or most) of their taxes all (or most) of the time, regardless of the financial incentives they face from the enforcement regime.

The basic model of individual compliance behavior therefore implies that rational individuals (especially those whose incomes are not subject to third-party sources of information) should report virtually no income. Although compliance varies significantly across countries and across taxes and is often quite low, compliance seldom falls to a level predicted by the standard economic theory of compliance. It seems implausible that government enforcement activities alone can account for these levels of compliance; the basic model is certainly unable to explain this behavior. Indeed, the puzzle of tax compliance behavior may well be why people pay taxes, not why they evade them. This observation suggests that the compliance decision must be affected in ways not captured by the basic economics-of-crime approach.

This dilemma can be illustrated more precisely, using the standard model of the individual compliance decision. Suppose that the utility function of the individual is $I_{i}^{1-e} /(1-e)$, where the subscript $i$ refers to the state of the world $(i=C, N)$ and $e$ is a measure of the individual's constant relative risk aversion. Using the definitions of $I_{C}$ and $I_{N}$ in equations (1) and (2), the 
expected utility maximization generated by the solution to equation (3) can then be solved for the optimum amount of declared income $D^{*}$. Now suppose that $D^{*}$ is calculated for specific, realistic values of the various parameters. For example, if $t=0.4, f=2, p=0.02$, and $e=1$, then the individual will optimally declare no income. Very large values for relative risk aversion are required to generate compliance consistent with actual country experience. When $e=3$, declared income is only 14 percent of true income; when $e=5$, it is still only 44 percent; when $e=10$, it is 71 percent. Risk aversion must exceed 30 for compliance to exceed 90 percent. However, existing field evidence on the coefficient of relative risk aversion suggests that $e$ ranges between 1 and 2. Risk aversion must be abnormally large for behavior to be even roughly comparable to actual observed choices, even in many developing countries with low levels of compliance.

As another example of the difficulties of expected utility theory, denote the taxes paid by the individual on declared income as $T$, the fine on unreported income as $F$, the probability of detection $p$, and a fixed amount of income $I$. Then the expected utility of the individual if she declares no income is $p U(I-F)+(1-p) U(I)$, while the certain utility if she declares all income is $U(I-T)$. The maximum amount of taxes that the individual will voluntarily pay can be found by equating these two expressions and solving for $T$; that is; the individual will voluntarily pay taxes only until utility with full declaration equals expected utility with no declaration. Using a linear approximation for the utility function (or $U\left(I_{i}\right)=U(I)+U^{\prime}(I)\left(I-I_{i}\right)$ ), the solution for $T$ is $p F$, so that taxes equal the expected value of the penalty. An individual who paid more than the expected value of the penalty is worse off than if she played the audit lottery. Even if the fine is as high as half of income, a low value for the probability of detection suggests that voluntary compliance parties, which are used to verify items reported on individual income tax returns. 
will also be low. ${ }^{4}$

In short, the basic model of individual compliance behavior therefore implies that rational individuals should report virtually no income. Although compliance varies significantly across countries and across taxes, and is often quite low, compliance seldom falls to a level predicted by the standard economic theory of compliance. It seems implausible that government enforcement activities alone can account for these levels of compliance; the basic model, in its reliance on expected utility theory, is certainly unable to explain this behavior. Indeed, the puzzle of tax compliance behavior is why people pay taxes, not why they evade them (Alm, McClelland, and Schulze, 1992). This observation suggests that the compliance decision must be affected by other factors or be affected in ways not captured by the basic economics-of-crime approach.

There have been many extensions of the basic economics-of-crime approach. One type of extension essentially adds a range of considerations that make the model more realistic, including such factors as: an individual labor supply decision, including the choice of sector in which to work; multiple individual strategies for reporting (e.g., simultaneous tax avoidance and tax evasion decisions); alternative penalty, tax, and tax withholding functions; complexity and uncertainty about the relevant fiscal parameters; the receipt of government services financed by tax payments; positive (individual) rewards for honesty (e.g., eligibility for a lottery if found to be compliant); and endogenous audit selection rules that utilize information from tax returns to determine strategically whom to audit. These extensions considerably complicate the theoretical

\footnotetext{
${ }^{4}$ This problem with expected utility theory - that it is unable to explain adequately much the behavior of many taxpayers - is not limited to its tax compliance incarnation. Such anomalous behavior has frequently been found in many other areas of choice under uncertainty, particularly in those areas that involve low probability-high loss events (e.g., natural disasters), or in those areas where the decisions of individuals are interdependent and repeated (e.g., voluntary public good provision). Machina (1987) documents evidence showing that individuals do not typically behave in ways consistent with expected utility theory.
} 
analyses, and generally render clear-cut analytical results impossible. ${ }^{5}$ These extensions also retain the basic - and limiting - result: individuals focus exclusively on the financial incentives of the evasion gamble, and individuals pay taxes solely because they fear detection and punishment. $^{6}$

A second type of extension is especially relevant to the role of ethics in the compliance decision. This work has expanded the basic model of individual choice by introducing some aspects of behavior considered explicitly by other social sciences. Many of these aspects can be discussed under the rubric of "behavioral economics".

Of most importance here is, we believe, the role of "ethics". For example, there is much evidence of what may be termed a "social norm" of tax compliance. Although difficult to define precisely, a social norm can be distinguished by the feature that it is process-oriented, unlike the outcome-orientation of individual rationality. A social norm therefore represents a pattern of behavior that is judged in a similar way by others and that therefore is sustained in part by social approval or disapproval. Consequently, if others behave according to some socially accepted mode of behavior, then the individual will behave appropriately; if others do not so behave, then the individual will respond in kind (Frey and Torgler, 2007).

The presence of a social norm is also consistent with a range of approaches, including those that rely upon "social customs", even appeals to "patriotism" or appeals to "conscience", or upon individual feelings of "altruism", "fairness", "morality", "guilt", or "alienation". For example, Bosco and Mittone (1997) take an altruistic approach stressing that taxpayers are not only interested in their own welfare but are also concerned about the general welfare, so that their

\footnotetext{
${ }^{5}$ For example, if the basic model is expanded by assuming that individuals can simultaneously use two strategies to evade taxes (e.g., underreporting income and overstating deductions), then it is no longer possible to predict that increased penalties or probabilities of detection will reduce evasion. See Martinez-Vazquez and Rider (1995). ${ }^{6}$ Again, see Cowell (1990), Andreoni, Erard, and Feinstein (1998), Alm (1999), and Slemrod and Yitzhaki (2002).
} 
decision to evade is constrained by the knowledge that their evasion will reduce the amount of resources available for social welfare. Another theory is broadly related to Kant's definition of morality (Laffont, 1975; Sugden, 1984), and is based on the assumption that a "fair" tax is a tax that a taxpayer believes to be fair for all other taxpayers to pay. A false declaration will generate anxiety, guilt, or a reduction in the taxpayer's self-image. It is assumed that a taxpayer only experiences these detrimental effects if he believes that his tax share is lower than what is defined as fair; if he pays a higher amount, evasion can be seen as a sort of self-defence. Erard and Feinstein (1994) incorporate shame and guilt directly into the taxpayer's utility, by hypothesizing that a taxpayer feels guilty when he underreports and escapes detection yet conversely also feels ashamed when he underreports and gets caught. Gordon (1989) further modifies the standard model by including non-pecuniary costs of evasion. He appeals to the literature on social customs (Akerlof, 1980; Naylor, 1989) to provide a reason why utility loss can be incurred by the act of evading. A non-pecuniary or psychic cost increases as evasion increases. Myles and Naylor (1996) also argue that, if the psychic cost is due to the shame at prosecution, then the extent of evasion is irrelevant; if it is instead due to the fear of detection, then it should be dependent on the detection probability rather than the extent of evasion. They also suggest a model in which a social custom utility is derived when taxes are paid honestly, but that all the utility is lost when evasion is undertaken. In their model, taxpayers face a choice between evading or not; if a taxpayer chooses evasion, the standard model of tax evasion becomes operative. $^{8}$

Overall, this factor of taxpayer "ethics", broadly defined, suggests that an individual will comply as long as she believes that compliance is the "right thing to do". Conversely, if

\footnotetext{
${ }^{7}$ See Webley et al. (1991) for a discussion of many of these alternative theories.
} 
noncompliance becomes pervasive, then the ethics of compliance disappears. This perspective also suggests that, if government can affect the way in which the ethical dimension of compliance is perceived by taxpayers, then such government policies represent another, potentially significant tool in government's battle with tax evaders. Some possible such government policies that may affect these ethical dimensions are discussed later.

\section{Evidence from Empirical Analyses}

A fundamental difficulty in empirical work on tax compliance is the lack of reliable information on taxpayer compliance. After all, individuals have strong incentives to conceal their cheating. The best available source of information on compliance in the United States is the Taxpayer Compliance Measurement Program (TCMP) of the IRS. From 1965 to 1988, the IRS conducted detailed line-by-line audits of a stratified random sample of roughly 50,000 individual tax returns on a 3-year cycle. These audits yielded an IRS estimate of the taxpayer's "true" income, which allowed measures of aggregate income tax evasion (e.g. the tax gap) to be calculated and which also allowed researchers to examine the impact of policy changes on individual compliance. Such data are probably the most accurate that are available. Even so, TCMP data had some serious and well-recognized deficiencies: the audits did not detect all underreported income, nonfilers were not often captured, honest errors were not identified, and final audit adjustments were not included. Impertantly, $\underline{\mathrm{T}}$ These data are also now quite dated. ${ }^{9}$ The TCMP has now been replaced by the National Research Program (NRP), which examined roughly 46,000 randomly selected individual returns for the year 2001 (but only some of which were subject to line-by-line audits). NRP data are now being analyzed in detail.

To avoid the problems with the TCMP data, some researchers have used aggregate

\footnotetext{
${ }^{8}$ See also Vanberg (1994), Brekke, Kverndokk, and Nyborg (2003), and Ostling (2009).
} 
measures of evasion, such as the total amount of income reported on tax returns, or the gap between income reported on tax returns and income reported in the national income accounts. By necessity, these studies focus on the aggregate, not the individual, response. Moreover, evidence is only available for a limited amount of countries such as the U.S. or Switzerland. Some other researchers have used U.S. state-level reporting data to estimate the effects of changes in state audit rates on reported income. Unfortunately, however, these studies do not have direct measures of noncompliance; they must also contend with various econometric issues (e.g., the endogeneity of the audit rates), and they are unable to control for all variables that affect taxpayer reporting decisions, including changes in the tax laws and in economic conditions. State amnesty data have also been used by researchers. Amnesty participants must declare previously unreported income, so that their amnesty declaration can be used as a measure of evasion. However, only some individuals opt to participate in an amnesty, and these participants may not be representative of all taxpayers.

In an effort to test more directly the deterrence effects of audits, some researchers have conducted controlled field experiments, often with the help of tax authorities. This approach evokes the real processes in the usual environment outside a laboratory setting, and it helps to better test the effects of different instruments on taxpayers in the real situation. However, these field studies do not generate actual information on individual noncompliance, but instead have to focus on income reported by the taxpayers. They are also unable to provide any estimate of the actual response of individuals to changes in the relevant policy variable. Even so, some studies have analyzed the impact of moral persuasion on voluntary income tax compliance with a field experiment (Blumenthal, Christian and Slemrod, 2001; Torgler, 2004; Hasseldine et al., 2007),

\footnotetext{
${ }^{9}$ For example, see Clotfelter (1983), Witte and Woodbury (1985), and Dubin and Wilde (1988) for empirical work
} 
and their results suggest that moral suasion does not have a strong impact on tax compliance.

Still other researchers have used surveys of taxpayers, in part to assess factors such as taxpayer perceptions of the probability of detection, the fairness of taxation, and the responsiveness of government in the respondent's reporting decision. When used to examine an individual's actual compliance decisions, these surveys are subject to a number of methodological problems that make the reliability of their compliance data highly suspect. Individuals may not remember their reporting decisions, they may not respond truthfully or at all, and the respondents may not be representative of all taxpayers. Surveys are also unable to control for many relevant determinants of noncompliance, and they cannot determine the direction of causality between evasion and its determinants.

Impertantly, hHowever, survey information on taxpayer attitudes are not subject to these same limitations, and it is here that there is much emerging evidence on the role of ethics in compliance (Torgler, 2007; McGee et al., 2008).

In their entirety, these various empirical studies have generated some useful results. For example, the studies often demonstrate a significant, though diminishing, deterrent effect of higher audit rates. ${ }^{10}$ There is some empirical evidence that a higher fine rate leads to marginally more compliance, and there is also strong evidence that audit rates are endogenous.

Of most relevance here, the survey evidence consistently suggests that taxpayer ethics play a potentially important role in their (unobserved) compliance decisions (Song and Yarbrough, 1978; Yankelovich, Skelly, and White, Inc., 1984). There is much survey evidence

that utilizes the TCMP.

${ }^{10}$ There is also some evidence of a "spillover effect" from audits, or an increase in compliance independent of revenues generated directly from the audits and penalties themselves. For example, Dubin, Graetz, and Wilde (1990) find that, for every dollar of revenue produced because of taxpayer audits, an additional six dollars of revenue were generated from these indirect or "ripple" effects on individuals not actually audited. More recent work by Dubin (2007) estimates an even larger ripple effect (eight to twelve). 
from many countries that indicates that compliance is strongly affected by the strength and commitment to the ethics of tax compliance. These surveys conclude, among other things, that those who comply view tax evasion as "immoral", that compliance is higher if a "moral appeal" to taxpayer is made by government, that the low social standing of tax evaders can be an effective deterrent, that individuals with tax evaders as friends are more likely to be evaders themselves, and that compliance is greater in communities with a stronger sense of social cohesion (Frey and Torgler, 2007). Other survey evidence suggests that some people will not pay their taxes if they dislike the way their taxes are spent, if they feel they have no say in the decision process, if they feel that government is unresponsive to their wishes, or if they feel that they are treated unfairly by government; there is also some empirical, experimental, and simulation evidence that compliance is affected by the nature of the collective decision process, at least in democratic countries. For example, Alm and Torgler (2006) analyze tax ethics in the United States and in Europe, using a multivariate analysis of World Values Survey data, and they find that tax ethics in both the United States and in Switzerland - two countries with a strong direct democratic tradition - are higher than in other OECD countries. Torgler (2005) provides further evidence that the stronger is direct democracy in a jurisdiction the stronger is tax ethics, using within country data from Swiss surveys. Similarly, Feld and Frey (2002) conclude that differences in the treatment of taxpayers by the tax authority are decisive, based on their empirical results using a data from Switzerland. Overall, it seems clear that such moral sentiments play an important, perhaps a dominant role, in tax compliance. Indeed, Torgler and Schneider (2007) show empirically that tax morale matters quite significantly in the determination of the size of the shadow economy.

\section{Evidence from Experiments}


A third type of evidence on the role of ethics comes from laboratory experiments. The use of experiments in economics began in the early 1960s with the work of Nobel laureate Vernon Smith. Growth in its applications came with the establishment of a well-defined framework for experimental work, and it is now widely accepted as a methodological approach in the analysis of theory and policy.

Tax compliance is an area that seems especially amenable to laboratory experiments, given limitations in both theoretical and empirical approaches. As emphasized earlier, theoretical models are not able to incorporate fully, appropriately, or tractably many factors deemed relevant to the individual compliance decision. In a sense, theory is both too complex and too simple. It is only in the simpler models that clear-cut analytical results can be generated on the compliance impact of basic policy parameters; when more complex dimensions of individual behavior are introduced, the theoretical results generally become ambiguous. Paradoxically, theoretical models of individual choice are also too simple. There are numerous factors that affect the reporting decisions of individuals, but theoretical models are capable of including only a few.

Empirical studies of tax compliance also have difficulties. As discussed earlier, empirical work is plagued by the absence of reliable information on individual compliance decisions. It is difficult to measure - and measure accurately - something that by its very nature people want to conceal. Relatedly, it is difficult to control in econometric work for the many factors that may affect the compliance decision.

In contrast, laboratory methods allow many factors suggested by theory to be introduced in experimental settings. Also, experiments generate precise data on individual compliance decisions, which allow econometric estimation of individual responses in ways that are simply 
not possible with field data. ${ }^{11}$ Examining with field data the impact of many factors often deemed important in compliance decisions (e.g., public good provision, audit selection rules, social processes and institutions) is also problematic. Indeed, laboratory methods have examined a wide range of factors in the compliance decision, factors that have not proven amenable to either theoretical analyses or empirical analyses with field data. There are some obvious limitations of experimental methods. However, given the weaknesses of other methodologies, we believe that there are compelling reasons for the use of experiments.

Experimental economics involves the creation of a real microeconomic system in the laboratory, one that parallels the naturally occurring world that is the subject of investigation. The essence of such a system is control over the environment, the institutions, and the preferences that subjects face. Of these, control over preferences is particularly crucial. Such control can be achieved by using a reward structure that induces prescribed monetary value on actions; that is, the investigator specifies a system by which subjects are paid, so that the amount earned by a subject is determined exclusively by the skill of the subject in figuring out the prescribed rules of the game.

In the area of taxpayer compliance, the basic design of most compliance experiments is similar. Human subjects in a controlled laboratory are told that they should feel free to make as much income as possible. At the beginning of each round of the experiment, each subject is given income and must decide how much income to report. Taxes are paid at some rate on all reported, but not on any underreported, income. However, underreporting is discovered with some probability, and the subject must then pay a fine on unpaid taxes. This process is repeated for a given number of rounds. At the completion of the experiment, each subject is paid an

\footnotetext{
${ }^{11}$ For example, penalty rates do not vary exogenously across individuals, and so it has not been possible to estimate
} 
amount (the accumulated earnings) that depends on his or her performance during the experiment. Into this microeconomic system, various policy changes can be introduced, such as changes in audit probabilities or audit rules, in penalty rates, in tax rates, and in any other relevant institutions.

As discussed in detail by Alm and Jacobson (2007), a wide range of issues has been examined using laboratory methods. One strand of work examines the impact of standard factors (e.g., audit rates, audit selection methods, fine rates) on compliance. Another strand demonstrates that subject compliance is higher than predicted by expected utility, a result that implies - but does not prove - that ethics may be an important missing element in the theory. For example, there is some work by Kahneman and Tversky (1979) that suggests that many subjects substantially “overweight” the probability of an audit, giving more weight to the probability of an event than they would relative to an expected utility perspective, so that there is far more compliance than is predicted by expected utility theory. Indeed, this type of result is nearly universal across all experimental designs.

Still other work provides more direct evidence on the role - and the importance - of ethics in the compliance decision. There is some experimental evidence that social norms can be affected by the institutions that face individuals, by individuals' attitudes toward these institutions, and by individual participation in the selection of those institutions (Alm, Jackson and McKee, 1993; Alm, McClelland and Schulze, 1999; Torgler and Schaltegger, 2005). Also, compliance is decreased, often collapsing virtually to zero, when there is a social expression via group selection by voting of the fiscal regime of a willingness to tolerate tax evasion, such as a majority vote in favor of reduced enforcement on detected evasion; however, compliance can be 
increased when there is a social expression of an unwillingness to tolerate tax evasion. It is as if the group decision to reject more enforcement ratifies each individual's decision to evade his taxes, and individual noncompliance is in some sense now justified by the revealed actions of others. This experimental evidence also suggests that Impertantly, the ethics of tax compliance can be affected by group communication. When subjects are allowed to communicate before a vote is taken (e.g., "cheap talk"), subjects select a greater level of enforcement, and the level of reporting approaches full compliance; that is, the cheap talk changes the group perception of the ethical dimension of tax compliance, so that paying taxes became the accepted and moral mode of behavior.

Other experiments further demonstrate the role of ethics in compliance. For example, there seem to be significant differences in the compliance behavior of student subjects in similar experiments but in different countries (Spain versus the United States (Alm, Sanchez and De Juan, 1995), or South Africa versus Botswana (Cummings et al., 2009), thereby suggesting that societal attitudes toward compliance exert a measurable impact on tax compliance. More recently, some studies try to use more than one methodology to explore the same question. For example, Alm and Torgler (2006) use World Values Survey data on Spain versus the United States from three different waves to estimate directly the determinants of tax ethics in Spain and the United States, and they find consistent evidence that individuals in the United States have a statistically significant higher tax ethic than those in Spain.

There are of course reasons for caution in the use and interpretation of experimental economics. Some early compliance experiments did not follow some now widely accepted procedures of the experimental paradigm, such as the use of repeated experiments and neutral instructions. Much early work also lacked realism because values of the various policy 
parameters did not approximate real-world values. More recent experimental research has generally addressed these problems.

Even so, some concerns remain, some of which are more real than others. A common criticism of experimental economics is that the student subjects typically used may not be representative of taxpayers. However, there is now much evidence that the experimental responses of students are seldom different than the responses of other subject pools. There is also no reason to believe that the cognitive processes of students are different from those of "real" people. Another common criticism is that it is not possible to control for many relevant factors in the laboratory. However, if one cannot control for such factors in the laboratory where the experimenter establishes the institutions, the rules, and the reward structure, then one cannot hope to control for these factors in the naturally occurring world.

Of more legitimate concern, the results may well be sensitive to the specific experimental design, so that replication is crucial. It is also possible that subjects may modify their behavior simply because they know that they are participating in an experiment, exhibiting more "obedience to authority" and more "pro-social behavior" in the laboratory than in the naturally occurring world (Levitt and List, 2007). Most critically, importantly, there is a certain artificiality in any laboratory setting. A decision to report, say, three tokens of income in a tax compliance experiment is clearly different from a decision to report actual income on an annual tax return, even if the laboratory incentives are salient. In particular, the laboratory setting cannot capture a catastrophic loss such as jail, and it cannot capture the social stigma that some surveys suggest is an important factor in taxpayer reporting.

In short, one must use the results from laboratory experiments with some care. However, such use depends largely upon the purpose of the experiment. According to Roth (1987), 
experiments can be classified into three broad categories that depend upon the dialogue in which they are meant to participate. "Speaking to Theorists" includes those experiments designed to test well-articulated theories. "Searching for Facts" involves experiments that examine the effects of variables about which existing theory has little to say. "Whispering in the Ears of Princes" identifies those experiments motivated by specific policy issues. To date, most experiments in tax compliance have fallen into the first two categories (Torgler, 2002), although there is now some evidence that the princes in the castles of tax administration are beginning to understand and to appreciate the ability of experimental analyses to illuminate some aspects of traditional public economics questions.

\section{Incorporating Ethics in the Theory of Compliance}

Given this previous work that, we believe, demonstrates the crucial importance of "ethics" in tax compliance, here we suggest several possible avenues by which the theory of tax compliance might be extended to incorporate ethics. Any theory must, we believe, incorporate the main elements that enter the compliance decision. These factors clearly include the fear of detection and punishment. However, additional factors also affect compliance. The main factor of concern here is of course ethics. As noted earlier, Aanother set of factors is suggested by the work of Kahneman and Tversky (1979), who argue that individuals may “overweight" low probabilities, giving more weight to the probability of an event than they would relative to an expected utility perspective, and also that they judge outcomes relative to some "reference point". These factors have either been ignored or been dealt with inadequately by expected utility theory. It is, however, possible to incorporate all of them in a formal theory of compliance, one that is much richer and is able to predict levels of compliance closer to those actually observed 
than expected utility theory. ${ }^{12}$

Adding a Simple Loss in Utility from "Unethical” Behavior

There are several ways in which the role of ethics can be introduced in the model of self-interested individual behavior. Perhaps the simplest way is suggested by Kahneman and Tversky (1979), who incorporate what they term a "reference point" as a form of social norm in prospect theory. They assume that a loss in utility occurs if individuals do not achieve some reference point, a phenomenon they call "loss aversion". The loss may be avoided by reporting all income and paying all taxes; individuals who declare less than their full income and pay less than their full taxes will suffer a loss in utility.

More formally, assume that each individual maximizes expected utility, where income in the two states of the world is now defined not as in equations (1) and (2) but as

$$
I_{C}=I-t D-f[t(I-D)]-\gamma t(I-D)
$$$$
I_{N}=I-t D-\gamma t(I-D)
$$

Expected utility is still defined by equation (3). The individual now is assumed to suffer a psychological loss in expected income proportional to undisclosed taxes, and the coefficient $\gamma$ measures as a fraction how much the individual would pay to avoid the loss associated with each dollar of unreported taxes. It is straightforward to show that declared income is higher in this setting than in the basic economics-of-crime model discussed earlier.

Clearly, $\gamma$ is likely to be sensitive to the ethics of tax compliance. The stronger is the ethical norm to pay one's taxes fully, the more deviant the behavior of a non-compliant individual becomes, and the more loss the individual feels.

\footnotetext{
${ }^{12}$ There are of course many other elements that may enter the compliance decision. The Internal Revenue Service (1978) lists 64 factors that may affect compliance. However, most of these cannot be incorporated in any formal theory of compliance.
} 
Adding a Loss in Utility Relative to an "Ethical" Norm

A similarly motivated approach introduces an additional element in an individual's utility function, an element that incorporates the individual's self-perception of himself as an ethically motivated individual. Utility now becomes

$$
U=U(I, M)
$$

where the term $M$ is a measure of this ethical (or moral) self-perception. One potentially productive way of defining $M$ is in terms of the deviation of actual declared taxes from the level with full compliance. Here the individual views paying taxes as the normal, accepted, and ethical form of behavior, so that $M$ becomes a function of this difference, as in the specific function

(7) $\quad M=M(t D-t I)=-\alpha(t D-t I)^{2}$.

Under the linearization in equation (7), $M$ reaches a maximum (at zero) when $D=I$, or when the individual pays all legally due taxes, and $M$ is a minimum when $D=0$. This ethical selfperception also increases at a decreasing rate with declared income.

Income in the two states of the world can now be defined as in equations (1) and (2), and the individual then proceeds by maximizing as before expected utility in equation (3), substituting equation (6) (and equation (7)). This reformulation of the individual's problem can be shown (under some conditions) to generate higher levels of compliance than in the standard model.

\section{Adding Loss Aversion}

Another potentially fruitful modification is the incorporation of non-expected utility behavior into the analysis (e.g., individuals exhibiting loss aversion or more extreme forms of risk aversion, such as rank dependent expected utility), which generates predictions of compliance 
more consistent with observed behavior (Bernasconi, 1998). For individuals described by a rank dependent expected utility model, we can modify the basic maximization problem of equation (3) to one in which an individual maximizes

$$
E U(I)=g p U\left(I_{C}\right)+(1-g)(1-p) U\left(I_{N}\right)
$$

where $g$ serves to overweight the probability of the "bad" outcome (or detection and punishment). This alternative approach also helps illuminate the roles of information dissemination by the tax authority. Official information provided by the tax authority that describes audits and their effectiveness should increase the weighted probability of an audit. In contrast, if the information highlights the absence of audits or their lack of effectiveness, we would expect that the information would lower the weighted probability of an audit. This formulation can be shown to generate higher levels of compliance than the standard model of equations (1), (2), and (3).

\section{Using a Prospect Theory Approach}

One final modification to expected utility theory (among many other possible ones) incorporates all of these elements into a single framework. This approach builds upon prospect theory, developed by Kahneman and Tversky $(1979,2000)$. Prospect theory retains some of the features of expected utility theory. However, it also makes two important modifications.

A first factor is that many individuals apparently adapt to an unchanged environment and perceive stimuli relative to the environment. ${ }^{13}$ Many individuals react much differently to gains than to (equal-but-opposite valued) losses. Individuals may therefore act on the basis of a "value

\footnotetext{
${ }^{13}$ As argued by Kahneman and Tversky (1979):

"Our perceptual apparatus is attuned to the evaluation of changes or differences rather than to the evaluation of absolute magnitudes. When we respond to attributes such as brightness, loudness, or temperature, the past and present context of experience defines an adaptation level, or reference point, and stimuli are perceived in relation to this reference point. Thus, an object at a given temperature may be experienced as hot or cold to the touch depending on the temperature to which one has adapted. The same principle applies to nonsensory
} 
function" (rather than the utility function in the standard economic model. The value function is assumed to depend upon changes in income from some reference point, rather than the level of income itself. It is also assumed to be steeper for losses than for gains because a loss in income is disliked much more than an equal gain, and it is concave for gains (risk aversion) but convex for losses (risk seeking), so that individuals may exhibit risk-averse behavior when confronted with risky but positive gambles, while the same individuals may become risk-lovers when faced with gambles that involve possible losses. The relevance of these assumptions for tax compliance is subtle yet powerful. Since some individuals frame any payment of taxes as a loss, these individuals will be likely to engage in risk-seeking behavior; that is, these individuals will declare less income than predicted by the basic model of expected utility theory.

A second factor is the way in which individuals perceive probabilities. There is overwhelming evidence from psychology that individuals "overweight" the low probabilities that they face in tax compliance; that is, even when fully informed, individuals systematically act as if the probability of audit that they face is much higher than its actual probability. Overweighting of probabilities may therefore provide an additional explanation for tax compliance. If taxpayers give more weight to the probability of an audit than they ought to (at least relative to an expected utility model), then compliance will be greater than the level predicted by the standard economics approach.

These two considerations suggest modifications to the standard approach.

First, the utility function is replaced by a "value function" $v($.$) . Because an individual$ adapts to an unchanged environment and perceives stimuli relative to the environment, value is assumed to depend upon changes in income from some reference point, rather than the level of 
income itself. The value function is also assumed to be steeper for losses than for gains because a loss in income is disliked much more than an equal gain; it is concave for gains (risk aversion) but convex for losses (risk seeking), so that the marginal value of both gains and losses declines with their magnitude; and the left hand derivative of the function $v^{\prime}(0)^{-}$exceeds the right hand derivative $v^{\prime}(0)^{+}$at the origin, where a prime (') denotes a derivative.

Second, the probability is replaced with a "weighting function" $\pi(p)$ that depends positively upon the probability, but that overweights low probabilities and underweights high ones.

These assumptions are discussed in detail by Kahneman and Tversky $(1979,2000)$. They demonstrate that prospect theory is often better able to explain behavior under risk than expected utility theory. Recent experimental also suggests that prospect theory generally performs better than either expected utility theory or other theories of behavior under uncertainty. ${ }^{14}$

Consider the application of prospect theory to tax compliance. A crucial element is the definition of the individual's reference point from which changes in income are measured. Although many reference points are possible, there are two that seem likely. One is the initial level of income $I$. An individual who has $I$ as the reference point views cheating as the norm and paying any taxes as a loss. The changes in income if caught $\left(X_{C}\right)$ or if not caught $\left(X_{N}\right)$ are defined relative to this reference point, and become

$$
\begin{aligned}
& X_{C} \equiv I_{C}-I=-t D-f[t(I-D)] \\
& X_{N} \equiv I_{N}-I=-t D
\end{aligned}
$$

where $I_{C}$ and $I_{N}$ are defined by the original equations (1) and (2). The value $V$ of this prospect is then defined as

\footnotetext{
${ }^{14}$ There are, of course, other theories of behavior under uncertainty. See Machina (1987) for a survey.
} 


$$
V=v(-t D)+\pi(p) v(-f t(I-D))
$$

Note that $V$ is not written as $\pi(p) v\left(X_{C}\right)+\pi(1-p) v\left(X_{N}\right)$. This is because the individual pays taxes $t D$ in both states of the world, a certain loss that is valued as $v(-t D)$ and that is implicitly weighted with unity. After this editing adjustment, the individual faces a modified prospect of $\pi(p) v(-f t(I-D))+\pi(1-p) v(0)$, which equals $\pi(p) v(-f t(I-D))$ because $v(0)$ is assumed to equal 0 . It is $V$ that the individual maximizes by the choice of reported income.

A second possible reference point is $(I-t I)$, or the level of income less full taxes. Here the individual views paying taxes as the normal, accepted, and ethical form of behavior, and changes in income are evaluated relative to this norm. The changes in income and the value function are now modified to reflect this different reference point. Other reference points are of course possible. In all cases, comparative statics results can be derived in a straightforward manner.

Prospect theory cannot explain all compliance puzzles. However, it allows a much richer analysis than is possible with expected utility theory. It allows changes in policy parameters to affect individuals differently, if their reference points differ. It explains why some people report no income even when facing a high probability of detection, if they are risk seekers or if their norm is to evade. It incorporates ethics into the compliance decision of individuals via effects on the reference point. Perhaps of greatest importance, prospect theory suggests that compliance will be greater than implied by most any of the extensions of expected utility theory.

To illustrate this last point, consider an individual whose norm is to evade. As before, denote taxes paid as $T$ and the fine on unreported income as $F$. The maximum amount of taxes that the individual will voluntarily pay can be found as in our earlier discussion. With a linear approximation for the value function, the solution for $T$ is $\pi(p) F$. Recall that under expected utility theory $T=p F$. If individuals overweight low probabilities, then compliance under prospect 
theory will be higher than under expected utility theory. Similarly, if the individual's ethical norm is to pay taxes, then it is straightforward to show that $T=\pi(p)\left[v^{\prime}(0)^{-} / v^{\prime}(0)^{+}\right] F$. Since $v^{\prime}(0)^{-}$ $>v^{\prime}(0)^{+}$, predicted compliance increases still further.

In fact, many - if not all - of the various elements in the compliance decision are captured nicely in this last expression for $T$ : the fear of detection $(p)$ and punishment $(F)$, the overweighting of low probabilities $(\pi(p))$, and the role of ethics via reference points $\left(v^{\prime}(0)^{-}\right.$ $\left./ v^{\prime}(0)^{+}\right)$. It may well be that other approaches will emerge that can productively examine the compliance decisions of individuals. However, we believe that prospect theory provides a useful base upon which further analysis of tax compliance can build.

\section{Alternative Paradigms for Tax Administration}

It is useful to view a "tax administration" somewhat broadly, as a "production function" in which “inputs" like personnel, materials, information, laws, and procedures are used to produce several "outputs", the most important of which is government revenue but which also includes taxpayer satisfaction, equity, and social welfare.

With these goals in mind, tax administration typically emphasizes a variety of measures, including such traditional policies as introducing an effective audit program that identifies individuals who do not file tax returns as well as those who underreport income or overclaim deductions and credits, applying non-harsh penalties often and consistently, using sourcewithholding whenever possible, facilitating payments through the banking system, and making use of third-party sources of information to verify reporting behavior. These "inputs" view the taxpayer as a potential criminal who must be deterred from cheating, and are clearly aligned with the economics-of-crime perspective. 
However, it is increasingly the case that administrative "inputs" are not limited to these traditional enforcement mechanisms. Instead, tax administrations in many countries are also introducing policies that emphasize such things as developing taxpayer services to assist taxpayers in every step of their filing returns and paying taxes, broadcasting advertisements that link taxes with government services, simplifying taxes and the payment of taxes, and even promoting a taxpayer - and a tax administrator - "code of ethics". Put differently, the taxpayer is no longer seen simply as a potential criminal but as a potential client, one whose behavior depends upon her moral values. This new approach suggests several additional, different paradigms for tax compliance than the one that emerges from the traditional analysis, and paradigms for which there is much theoretical, empirical, and experimental support, as discussed earlier.

Three very different administrative paradigms can therefore be followed in encouraging tax compliance, each with very different implications for tax compliance behavior.

Under the first paradigm - the traditional "enforcement" paradigm - taxpayers are viewed and treated as potential criminals, and the emphasis is exclusively on repression of illegal behavior through frequent audits and stiff penalties. This has been the conventional paradigm of tax administrations throughout history, and it fits well the standard economic model of tax evasion based on the economics-of-crime theory.

A second paradigm recognizes the role of enforcement, but also recognizes the role of tax administration as a facilitator and a provider of services to taxpayer-citizens. This new "service" paradigm for tax administration fits squarely with the perspective that emphasizes the role of government-provided services as considerations in tax compliance. In fact, the most recent literature on tax administration reform has typically emphasized this new paradigm of the role of 
tax administration, as a facilitator and a provider of services to taxpayer-citizens, and many recent administrative reforms around the world have embraced this new paradigm with great success. One of the best examples is provided by Singapore's tax administration reform over the last several decades, the main tenet of which is service-oriented: the conversion from a hard-copy filing system to a paperless imaging system, the extensive use of electronic filing, a one-stop service to answer inquires about any type of tax, the ability for filers to see the entire tax form with any corrections before it is submitted, the use of interest-free installment plans for paying taxes with direct deduction from bank accounts, separate functional areas within the tax administration with little opportunity for corruption, and a changed attitude of officials toward taxpayers. The tax administration service of Singapore has gone from being the lowest rated government agency in public satisfaction to one that ninety percent of the taxpayers found to provide courteous, competent, and convenient services.

A third paradigm is also suggested by this work, especially the work that demonstrates the importance of ethics in tax compliance behavior. We term this a "trust" paradigm, and it is consistent with the role of morality, of social norms, and of other "behavioral economics" factors in the compliance decision.

How can these paradigms be used to devise to devise policies that encourage people in paying their taxes - or that discourage them in cheating on their taxes? These policies fall into three main categories, each consistent with one of the paradigms.

First, there is scope for an improvement in policies to increase detection and punishment (e.g., the "enforcement" paradigm). Traditionally, there are three main aspects of tax administration: taxpayer registration, taxpayer audit, and collections. Improvements in each of these areas are feasible, all of which would enhance detection and punishment: 
- Increase the number of audits, either by hiring additional auditors or by contracting out audits to for-profit firms.

- Improve the quality of audits - and of the auditors.

- Increase penalties for tax cheating, such as the interest rate on unpaid taxes.

- Publicize tax evasion convictions in the media as an alternative, non-financial type of penalty.

- Improve the effectiveness of audits via adoption of modern audit technology, including more systematic selection of returns for audit and greater use of "scoring" tax returns. ${ }^{15}$

- Apply non-harsh penalties often and consistently, facilitate payments through the banking system, allow for simple cross-tax deductions (e.g., interests payments on loans or mortgages), and rely more heavily on source-withholding.

- Grant additional power for collecting delinquent accounts. For example, in addition to imposing interest and fines for late reporting, the tax administration could be given the power to revoke business licenses or driver's licenses.

- Increase taxpayer registration and identification via better use of third-party information, such as use of cross-referencing between different taxes (e.g., checking sales tax vendors against income tax returns) or use of social security records, phone records, financial system data, and agency data bases such as driver's licenses to identify potential nonfilers.

In addition to these somewhat standard suggestions, tax administrations might consider actions like disallowing cash deductions unless the taxpayer identifies the person or firm that was paid, requiring increased information from selected taxpayers, expanding source-withholding, and even expanding information-sharing between states, as well as between the states and the federal government.

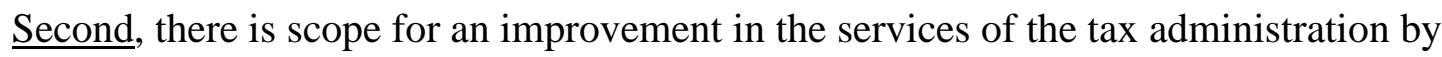
becoming more "consumer-friendly", along the lines of the "service" paradigm of tax administration:

- Promote taxpayer education.

- Provide taxpayer services to assist taxpayers in filing returns and paying taxes.

- Improve phone advice service.

- Improve the tax agency website.

- Simplify taxes.

- Simplify the payment of taxes.

- Simplify tax forms.

The basic thrust of these "service" paradigm actions is to treat the taxpayer more as a client than

15 "Scoring" is a way of ranking taxpayers for audit purposes that uses various characteristics of the taxpayer such as 
as a potential criminal.

Third, there may be scope for a governmental-induced change in the culture of paying taxes, also consistent with the "trust" paradigm:

- Use the mass media to reinforce tax compliance as the ethical form of behavior - and publicize cheaters.

- Emphasize the link between payment of taxes and the receipt of government services.

- Target certain groups (e.g., new firms or employees) in order to introduce from the start the notion that paying taxes is "the right thing to do".

- Enlist other organizations to promote compliance, so that it is seen (again) that paying taxes is the accepted and ethical pattern of behavior.

- Avoid leading individuals to think cheating is "okay" - a tax amnesty is a classic example of sending the wrong signal.

- Address perceived inequities in the ways people feel that they are treated.

It is this third paradigm that is, we believe, an essential but largely neglected strategy for improving compliance and one that relies squarely on the importance of ethics in compliance.

\section{Conclusions}

$\underline{\text { It is course arguable whether a legitimate goal of government is to improve its ability to collect }}$ $\underline{\text { taxes from its citizens. However, once this goal is acknowledged, then strategies to improve }}$ compliance are needed. We argue in this paper that Aan administrative compliance strategy based only on enforcement may well be a reasonable starting point but is not a good ending point for closing the tax gap. Instead, what is needed is a multi-faceted policy approach that emphasizes enforcement, but one that also emphasizes such things as service and, especially, trust. Put differently, detection and punishment must be present - the "punishment" paradigm but other tools are needed to be used as well, tools that reflect the provision of better services to taxpayers consistent with the "service" and "trust" paradigms. In short, there should be a wide

sources of income and the magnitude of particular deductions, as well as a scheme for weighting these factors. 
range of administrative policies.

In this regard, recent work by Gould (1996) emphasizes that it is grossly misleading to represent a complex system by a single, so-called representative agent, who behaves in some average or typical way. Instead, most systems have incredible variety - a "full house" of individual behaviors - and the proper understanding of any system requires recognition of this basic fact. Indeed, Gould (1996) argues that the way in which a system changes over time is attributable largely to changes in the amount of variation within the system, rather than to changes in some largely meaningless "average" behavior across its individual members.

This lesson is especially apt for tax compliance, and for administrative options to close the tax gap. People exhibit a remarkable diversity in their behavior. There are individuals who always cheat and those who always comply, some who behave as if they maximize the expected utility of the tax evasion gamble, others who seem to overweight low probabilities, individuals who respond in different ways to changes in their tax burden, some who are at times cooperative and at other times free-riders, and many who seem to be guided by such things as social norms, moral sentiments, and tax equity, factors that we have broadly classified as "ethics". Indeed, there is now much evidence that, contrary to the standard neoclassical approach to consumer choices, individuals are not always purely self-interested, they face limits on their ability to compute (e.g., "bounded rationality"), they systematically misperceive the true cost of actions (e.g., "fiscal illusion"), they face limits on their "self-control," and they are affected by the ways in which choices are "framed" (e.g., reference points, gains versus losses, loss aversion). As emphasized throughout our paper here, there is also much evidence that individuals are influenced by the ethical dimensions of their decisions; that is, individuals are not always the outcome-oriented, egoistic, and selfish consumers envisioned by our standard theory but are 
affected in predictable ways by the processes by which outcomes are determined and also by notions of fairness, altruism, reciprocity, trust, social norms, and, more broadly, ethics.

Any government administrative approach toward tax compliance must address this "full house" of behaviors in devising policies to ensure compliance. Consequently, a compliance strategy based only on detection and punishment may well be a reasonable starting point for tax administration but not a good ending point. Instead, what is needed is a multi-faceted administrative approach that emphasizes enforcement, but that also emphasizes the much broader range of actual motivations, including ethics, that explain why people pay taxes.

\section{References}

Akerlof, G. A.: 1980, 'A Theory of Social Custom of Which Unemployment May Be One Consequence’, Quarterly Journal of Economics 94, 749-795.

Allingham, M. G. and A. Sandmo: 1972 'Income Tax Evasion: A Theoretical Analysis', Journal of Public Economics 1, 323-338.

Alm, J.: 1999, ‘Tax Compliance and Administration', in W. B. Hildreth and J. A. Richardson (eds.), Handbook on Taxation (Marcel Dekker, Inc., New York, NY, 741-768).

Alm, J. and S. Jacobson: 2007, 'Using Laboratory Experiments in Public Economics', National Tax Journal 60, 129-152.

Alm, J. and B. Torgler: 2006, 'Culture Differences and Tax Morale in the United States and Europe', Journal of Economic Psychology 27, 224-246.

Alm, J., B. R. Jackson, and M. McKee: 1993, 'Fiscal Exchange, Collective Decision Institutions, and Tax Compliance', Journal of Economic Behavior and Organization 22, 285-303.

Alm, J., G. H. McClelland, and W. D. Schulze: 1999, 'Changing the Social Norm of Tax Compliance by Voting', KYKLOS 48, 141-171.

Alm, J., I. Sanchez, and A. De Juan: 1995, 'Economic and Noneconomic Factors in Tax Compliance', KYKLOS 48, 3-18.

Andreoni, J., B. Erard, and J. Feinstein: 1998: 'Tax Compliance,' The Journal of Economic Literature 36, 818-860.

Becker, G.S.: 1968, 'Crime and Punishment - An Economic Approach', The Journal of Political Economy 76, 169-217.

Bernasconi, M.: 1998, 'Tax Evasion and Orders of Risk Aversion', Journal of Public Economics 67, 123-134.

Bosco, L. and L. Mittone: 1997, 'Tax Evasion and Moral Constraints: Some Experimental Evidence', KYKLOS 50, 297-324. 
Blumenthal, M., C. Christian and J. Slemrod: 2001, 'Do Normative Appeals Affect Tax Compliance? Evidence from a Controlled Experiment in Minnesota', National Tax Journal 54, 125-138.

Brekke, K.A., S. Kverndokk, and K. Nyborg: 2003: 'An Economic Model of Moral Motivation', Journal of Public Economics 87, 1967-1983.

Clotfelter, C. T.: 1983, 'Tax Evasion and Tax Rates: An Analysis of Individual Returns', The Review of Economics and Statistics 65, 363-373.

Cowell, F.: 1990, Cheating the Government: The Economics of Evasion (The MIT Press, Cambridge, MA).

Cummings, R. G., J. Martinez-Vazquez, M. McKee, and B. Torgler: 2009, 'Tax Morale Affects Tax Compliance: Evidence from Survey and an Artefactual Field Experiment', Journal of Economic Behavior and Organization 70, 447-457.

Dubin, J. A.: 2007, 'Criminal Investigation Enforcement Activities and Taxpayer Noncompliance', Public Finance Review 35, 500-529.

Dubin, J.A., M. J. Graetz, and L. L. Wilde: 1990, 'The Effect of Audit Rates on the Federal Individual Income Tax, 1977-1986', National Tax Journal 43, 395-409.

Dubin, J.A. and L.L. Wilde: 1988, 'An Empirical Analysis of Federal Income Tax Auditing and Compliance', National Tax Journal 41, 61-74.

Elffers, H.: 1991. Income Tax Evasion: Theory and Measurement (Kluwer, Amsterdam, The Netherlands).

Erard, B. and J. S. Feinstein: 1994, 'The Role of Moral Sentiments and Audit Perceptions in Tax Compliance', Public Finance 49, 70-89.

Feinstein, J.S.: 2007: 'Review of The Bourgeois Virtues: Ethics for an Age of Commerce', The Journal of Economic Literature 45, 466-479

Feld, L. P. and B. S. Frey: 2002, 'Trust Breeds Trust: How Taxpayers are Treated', Economics of Governance 3, 87-99.

Frey, B. S. and B. Torgler: 2007, 'Tax Morale and Conditional Cooperation', Journal of Comparative Economics 35, 136-159.

Gordon, J. P. F.: 1989, 'Individual Morality and Reputation Costs as Deterrents to Tax Evasion', European Economic Review 33, 797-805.

Gould, S. J.: 1996, Full House (Harmony Books, New York, NY).

Graetz, M. J. and L. L. Wilde: 1985, 'The Economics of Tax Compliance: Fact and Fantasy', National Tax Journal 38, 355-363.

Hasseldine, J., P. Hite, S. James, and M. Toumi: 2007, 'Persuasive Communication: Tax Compliance Enforcement Strategies for Sole Proprietors', Contemporary Accounting Research 24, 171-194.

Internal Revenue Service, United States Department of the Treasury: 1978, A Dictionary of Compliance Factors (Government Printing Office, Washington, D. C).

Kahneman, D. and A.Tversky: 1979, 'Prospect Theory: An Analysis of Decision under Risk', Econometrica 47, 263-291.

Kahneman, D. and A. Tversky: 2000, Choices, Values, and Frames (Cambridge University Press, Cambridge, UK).

Laffont, J. J.: 1975, 'Macroeconomic Constraints, Economic Efficiency and Ethics: an Introduction to Kantian Economics', Economica 42, 430-437.

Levitt, S. D. and J. A. List: 2007, 'What Do Laboratory Experiments Reveal About the Real World?', The Journal of Economic Perspectives 21, 153-174. 
Machina, M.: 1987, 'Choice under Uncertainty: Problems Solved and Unsolved', The Journal of Economic Perspectives 1, 121-154.

Martinez-Vazquez, J. and M. Rider: 1995, 'Multiple Modes of Evasion: Theory and Evidence,' National Tax Journal 58, 51-76.

McCloskey, D. N.: 2006, The Bourgeois Virtues: Ethics for an Age of Commerce (University of Chicago Press, Chicago and London).

McGee, R. W., S. S. M. Ho, and A. Y. S. Li: 2008, 'A Comparative Study on Perceived Ethics of Tax Evasion: Hong Kong Vs the United States', Journal of Business Ethics 77, 147-158.

Myles, G. D. and R. A. Naylor: 1996, 'A Model of Tax Evasion with Group Conformity and SocialCustom', European Journal of Political Economy 12, 49-66.

Naylor, R. A.: 1989, 'Strikes, Free Riders and Social Customs', Quarterly Journal of Economics 104, 771-805.

Ostling, R.: 2009, 'Economic Influences on Moral Values', The B.E. Journal of Economic Analysis and Policy 9 (1), Article 2.

Roth, A. E.: 1987, 'Laboratory Experimentation in Economics' in T. Bewley (eds.), Advances in Economic Theory, Fifth World Congress (Cambridge University Press, Cambridge, UK, 269299).

Schneider, F. and D. Enste: 2000, 'Shadow Economies: Size, Causes, and Consequences', The Journal of Economic Literature 38, 77-114.

Skinner, J. and J. Slemrod: 1985, 'An Economic Perspective on Tax Evasion', National Tax Journal, 38, 345-353.

Slemrod, J., M. Blumenthal, and C. Christian: 2001, 'Taxpayer Response to an Increased Probability of an Audit: Evidence from a Controlled Experiment in Minnesota', Journal of Public Economics, 79, 455-483.

Slemrod, J. and S. Yitzhaki: 2002, 'Tax Avoidance, Evasion, and Administration', in A. J. Auerbach and M. Feldstein (eds.), Handbook of Public Economics (Elsevier, Amsterdam, London, and New York, 1423-1470).

Song, Y. and T. E. Yarbrough: 1978, 'Tax Ethics and Taxpayer Attitudes: A Survey', Public Administration Review 38, 442-452.

Sugden, R.: 1984, 'Reciprocity: the Supply of Public Goods through Voluntary Contributions', Economic Journal 94, 772-787.

Torgler, B.: 2002, 'Speaking to Theorists and Searching for Facts: Tax Morale and Tax Compliance in Experiments', Journal of Economic Surveys 16, 657-684.

Torgler, B.: 2004, 'Moral Suasion: An Alternative Tax Policy Strategy? Evidence from a Controlled Field Experiment in Switzerland', Economics of Governance 5, 235-253.

Torgler, B.: 2005, 'Tax Morale and Direct Democracy', European Journal of Political Economy 21, 525-531.

Torgler, B. and C. A. Schaltegger: 2005. 'Tax Amnesties and Political Participation', Public Finance Review 33, 403-431.

Torgler, B. and F. Schneider: 2007. 'Shadow Economy, Tax Morale, Governance and Institutional Quality: A Panel Analysis', School of Economics and Finance Discussion Papers and Working Papers Series 210, School of Economics and Finance, Queensland University of Technology.

Vanberg, V.J.: 1994, 'Morality and Economics: De Moribus est Disputandum', in V.J. Vanberg (ed.), Rules and Choice in Economics (Routledge, London and New York, 41-59).

Webley, P., H.S.J. Robben, H. Elffers, and D.J. Hessing: 1991, Tax Evasion: An Experimental 
Approach (Cambridge University Press, Cambridge, UK).

Witte, A.D. and D.F. Woodbury: 1985, 'The Effect of Tax Laws and Tax Administration on Tax Compliance National Tax Journal 38, 1-13.

Yankelovich, Skelly, and White, Inc.: 1984, 'Taxpayer Attitudes Survey: Final Report', Public Opinion Survey Prepared for the Public Affairs Division, Internal Revenue Service (New York, NY, December 1984). 